\title{
Chapter 1 \\ From Resources to \\ Beneficiaries: Introducing \\ an End-to-End Resource \\ Tracking and Management \\ Framework and its Application \\ for Primary Health Care \\ Development in LMICs
}

Hong Wang, * Daniel H. Kress ${ }^{\dagger}$ and Peter Berman

*Senior Program Officer, Bill \& Melinda Gates Foundation, 5005 th Ave N, Seattle, WA 98109, USA

$\dagger$ Vice President, Global Health Systems Innovation,

Management Sciences for Health, 4301 North Fairfax Drive

Suite 400 Arlington, VA 22203, USA

$\$$ Professor and Director, School of Population and Public Health,

University of British Columbia, 2206 East Mall Room 117,

Vancouver, B.C. V6T1Z3, Canada 


\section{Key Messages}

- Financial resource tracking plays a critical role in providing important information to policymakers for evidence-based policy development and its implementation, especially for the effective and efficient functioning of the primary health care (PHC) system and achievement of global health-related goals.

- The resource tracking and management framework adds value by bringing disparate resource tracking efforts into one comprehensive structure. This enables policymakers to see the overall resources envelope and resource flows as a continuum: from the sources of financing to the beneficiaries. This provides a comprehensive picture of how resources are mobilized, deployed, and utilized to achieve intended outcomes.

- The resource tracking and management framework emphasizes that resource tracking is not just about getting the financial numbers and statistics, it is about the policy issues, analysis, interpretation, and overall storyline behind these numbers and statistics, which is critical for the health financing system diagnosis and problem identification, priority setting, and actionable solution development for improvement.

- Given its important roles in health care system development and in achieving global health-related targets, there is an imperative need to pay more attention and devote more efforts to tracking and managing PHC financial resources for better outcomes.

\section{The Need for Better Tracking and Managing Financial Resources for Primary Health Care}

In the latter part of the 20th century, borrowing from the experience in the development of the three-tier education system in Europe, primary care has been coined as the most basic level of care in a structured health system that is able to provide the most essential health care services in outpatient settings (Bitton et al., 2017). Since that time, the roles and functions of primary care have been reemphasized in the Health For All through the Primary Health Care (PHC) in the Declaration of Alma-Ata in 1978 and for the achievement of Millennium Development Goals (MDG) in 2000. In the current Sustainable Development Goals (SDG) era, PHC has been considered essential to achieve health-related SDG 
targets without leaving anyone behind. PHC has been considered as the priority in an integrated health service system to address key health care issues such as maternal, neonatal, and child health care; sexual and reproductive health services; as well as the prevention and treatment of substance abuse and prevention and treatment non-communicable diseases (NCDs). PHC has also been considered as the necessary foundation for achieving Universal Health Coverage (UHC) and has increasingly been recognized as the cornerstone of the health care system. PHC is also viewed as the most effective, efficient, and equitable approach to deliver essential services to the vast majority of the population as well as an approach that will reduce the overall cost of health care services (Frenk, 2009; Johnson, 2008; Millis, 1966; Veillard et al., 2017).

Despite the global recognition of the importance of the PHC within the health care system and the political commitments from countries and global communities to build a strong PHC, PHC system development is still falling short in many low- and middle-income countries (LMICs) due to various reasons, but particularly due to issues in PHC financing. On one hand, there is an insufficient investment in health and health care development in many LMICs due to economic development constraints such that PHC has to compete with other health-related investments such as secondary and tertiary care and other priority programs within the health care system. On the other hand, there is a great need to improve the use of the existing financial resources made available to PHC. PHC is underfunded in many countries, but the reality is that often the funds made available for PHC are not used efficiently, effectively, and equitably.

Given the high-level political commitments towards PHC system development and critical challenges in financing for $\mathrm{PHC}$, understanding resource flows and tracking those flows for PHC system development and service delivery are of greater and greater interest. The global health community is broadly in agreement that achievement of the health-related SDGs hinges upon both an escalation of the financial resources dedicated to PHC and a more effective use of those resources, i.e., more money, better spent.

This volume presents evidence from LMICs on the value of applying a comprehensive resource tracking and management framework in analyzing PHC resources. This framework identifies five components that determine effective financing for PHC. These are resource mobilization, allocation, utilization, productivity, and targeting. 
Resource mobilization, allocation, utilization, productivity, and targeting issues are critical ingredients in the health impact causal chain as these are the links that determine levels of health spending and the efficiency and effectiveness of health spending. First, resource mobilization affects resource availability for sustainable impacts at a large scale; second, resource allocation, utilization, and productivity affect efficiency and effectiveness of health service delivery; and third, resource targeting is about government responsibility and accountability for health investments that benefit poor and vulnerable populations. Financial resource tracking and management provides critical information to policymakers for evidence-based policy development that can ensure more spending on health and greater effectiveness of that spending.

Development assistance for health (external funding for health) grew rapidly prior to the global economic recession that began in 2008-2009. However, since then development assistance for health has largely plateaued, and even declined some years. The global economic slowdown also impacted domestic funding for health, which has been largely flat with the exception of a few countries with more robust growth and a high commitment to funding health. Taken together, these developments put new urgency on the need to improve the efficiency of health spending and getting "value for money" - a theme that has emerged as a key priority for developing country governments and development partners. This in turn has led global health stakeholders to focus attention on improving resource tracking efforts to generate information about how scarce health resources for primary care are allocated, managed, and used and to emphasize more on the improvement of existing resource utilization and reduce causes of weak service delivery performance.

Lastly, but not least, due to the increased transparency and accountability requests from country governments, donors, and the international development community, advocacy groups are devoting more energy to ensure both country governments and donors live up to their political and financial commitments to improve PHC system development and performance.

Given the high demand for information and accountability from multiple stakeholders, attention has increased on resource tracking activities. Many resource tracking methods and tools have been developed and 
implemented in the past few decades. For example, the public expenditure tracking efforts and methods were developed and became more common and widely instituted to track the poverty-reducing public spending under the Enhanced Highly Indebted Poor Countries (HIPC) Initiative in the early 2000s (IMF, 2001). While this early effort focused on the povertyreducing public spending, the approaches and methods were adopted quickly in the health sector. Currently, the health expenditure analysis, health accounting, health resource flow tracking, and other related analyses with various terms have become routine exercises in many higher income countries and are increasingly being adopted as regular parts of health system and financing assessments in LMICs.

Regardless of the long history of the evolution of resource tracking efforts, these efforts applied to PHC specifically are still rather limited and fragmented, and the results of these efforts are typically not publicly available. In addition, there is very little information on how these efforts are actually affecting policy development and its implementation.

Here are some early examples of resource tracking for PHC that exist and are worthy of note. Among the existing PHC resource tracking efforts, most focus on expenditure tracking. Many of them are one-off efforts with different definitions, methods, and approaches, which thus hinder comparability. For example, The World Bank conducted a case study of Improving Universal Primary Health Care in Kenya. The results showed that PHC spending as a percentage of total health spending was about $40.3 \%$ in $2009 / 10$. This figure was about $37.6 \%$ in $2001 / 02$. PHC expenditure is defined by spending by PHC providers, which include health centers, dispensaries, community health workers, and providers of health programs (Ramana et al., 2013).

South Africa's Health System Trust has published public expenditure information on PHC in South Africa. This public expenditure on PHC includes the expenditure for district management, services at clinics, and community health care and community-based services. The average per capita PHC spending increased by 66\% from R232 in 2005/06 to R386 in 2010/11 (real terms) (Naledi et al., 2011).

India's Commission on Macroeconomics and Health estimated public spending on primary, secondary, and tertiary cares in 13 states in India in years prior to 2001. Primary care services are defined as the services 
provided at primary health centers, health sub-centers, other health services, school health schemes, public health, and family welfare. The share of public PHC expenditure in total public health expenditure ranged from $20.9 \%$ in Maharashtra to 46.7\% in Andhra Pradesh in 1998/99 and the real per capita public PHC expenditure ranged from Rs. 6.1 in Uttar Pradesh to Rs. 17.9 in Tamil Nadu in 1998/99 (Selvaraju and Annigeri, 2001).

Based on national health account (NHA) data from 2004-2005 in India, about $62.5 \%$ of total health expenditure (THE) was spent on PHC-related services. In other words, of the per capita THE of US\$20.5, US\$12.8 was spent on PHC in 2004-2005 (US\$1 = INR 60). Of the per capita PHC expenditure of US\$12.8, the government accounted for only US $\$ 1.7$ per capita or $13 \%$ of total $\mathrm{PHC}$ expenditure, while the remaining was from private expenditure, including a very small amount of donor expenditure (National Health Accounts Cell, 2009).

The office of the Health Insurance Commissioner in the state of Rhode Island conducted an analysis of primary care spending in Rhode Island using three health insurance data sets: Blue Cross Blue Shield of Rhode Island (BCBSRI), United Health Care (United), and Tufts Health Plan (Tufts) in 2014. The results showed that primary care spending as a percentage of total medical spending in 2012 was $9.4 \%$ in BCBSRI, $8.5 \%$ in United, and $8.2 \%$ in Tufts. These three figures were around $5.5 \%-5.8 \%$ in 2008 . The increase in primary care spending was considered a positive sign for controlling costs. The report did not provide a per capita PHC expenditure figure (Office of the Health Insurance Commissioner, 2014).

One of the more recent large-scale efforts on PHC expenditure tracking at the global level is the World Health Organization's (WHO) System of Health Accounts (SHA 2011) analysis. In 2018, WHO estimated PHC expenditure in selected LMICs and published a conference paper in Astana at the 40th anniversary of the Alma-Ata conference on PHC in October 2018 (Maele et al., 2008). This is the first attempt by the WHO to publish estimates of PHC expenditure globally. The results showed that PHC services comprise 54\% of total current health care expenditure in the sample of countries studied. Annual per capita PHC expenditure is, on average, US\$36 per year (median of US\$23.8). Of this US\$36 per year, about $21 \%$ comes from the government, $24 \%$ from external resources 
Table 1: PHC Expenditures from 27 Low-income and Lower-middle-income Countries

\begin{tabular}{|c|c|c|c|c|c|c|c|c|}
\hline $\begin{array}{l}\text { Country } \\
\text { and Year }\end{array}$ & $\begin{array}{c}\text { Government } \\
\text { Health } \\
\text { Expenditure } \\
\text { as \% of } \\
\text { GDP }\end{array}$ & $\begin{array}{l}\text { PHC } \\
\text { Capita } \\
\text { (USD) } \\
\end{array}$ & $\begin{array}{l}\text { Government } \\
\text { as } \% \text { in } \\
\text { PHC } \\
\text { Expenditure }\end{array}$ & $\begin{array}{c}\text { External as } \\
\% \text { in PHC } \\
\text { Expenditure }\end{array}$ & $\begin{array}{c}\text { Others as } \\
\% \text { in PHC } \\
\text { Expenditure }\end{array}$ & $\begin{array}{c}\text { PHC as \% } \\
\text { in Current } \\
\text { Health } \\
\text { Expenditure }\end{array}$ & $\begin{array}{c}\text { Government } \\
\text { Allocated to } \\
\text { PHC } \\
\text { Expenditure } \\
\text { as } \% \text { in } \\
\text { GHE }\end{array}$ & $\begin{array}{c}\text { GDP per } \\
\text { capita } \\
\text { (USD) } \\
\end{array}$ \\
\hline \multicolumn{9}{|l|}{ Sub-LMIC } \\
\hline Mean & 1.6 & 46.9 & 25.3 & 10.7 & 64.1 & 49.8 & 32.3 & 1963.4 \\
\hline Median & 1.2 & 34.5 & 26.2 & 8.5 & 70.0 & 50.3 & 33.9 & 1465.0 \\
\hline \multicolumn{9}{|l|}{ Sub-LIC } \\
\hline Mean & 1.3 & 22.5 & 14.7 & 39.2 & 46.1 & 59.9 & 39.8 & 588.7 \\
\hline Median & 1.1 & 19.8 & 13.8 & 40.2 & 46.1 & 62.8 & 42.7 & 605.0 \\
\hline \multicolumn{9}{|c|}{$\begin{array}{l}\text { Total (LMIC } \\
\quad+\text { LIC) }\end{array}$} \\
\hline Mean & 1.5 & 36.0 & 20.6 & 23.8 & 55.8 & 54.3 & 35.6 & 1352.4 \\
\hline Median & 1.2 & 23.8 & 15.6 & 19.8 & 55.3 & 56.9 & 35.9 & 1059.0 \\
\hline
\end{tabular}

Note: Estimated from the data that are published in the WHO reports at the Astana PHC conference, October 2018 (Maele et al., 2008). 
(i.e., donors), and the remaining 55\% come from other sources, most of which is from out-of-pocket (OOP) expenses from patients directly (The WHO estimates combined out-of-pocket spending with other sources of spending in a single category. Other studies, however, often find that most of "others" is from OOP spending.) Governments in these LMICs allocate $36 \%$ of their total health investment to PHC.

There are a number of concerns about the accuracy of these first global estimates. For example, the SHA 2011 framework does not include a simple, applicable definition of PHC expenditure. Also, countries may apply different expenditure category definitions in different ways, which may make comparisons inaccurate; the quality of the data in some countries may also be poor. Despite the concerns, these estimates are the first attempt to provide a picture of how LMICs allocate/use their scarce health financial resources for PHC services. This effort is also one of the first that attempts to track the financial resources for PHC in a systematic manner across LMICs and over time.

The WHO team also projected resource needs to call for the increase of PHC investment, given its importance in achieving SDG and UHC goals. In 2017, the WHO financing team estimated the total investment needed to meet the SDGs. The results indicated that US\$3.9 trillion additional health investment is needed by the 67 LMICs over the next 15 years in order to meet the SDGs. This is about US\$58 per capita per year, which is the average figure needed during 2026-2030, reflecting the more mature scale-up phase (Stenberg et al., 2017, 2019). In order to specify the importance of $\mathrm{PHC}, \mathrm{WHO}$ also broke down this total investment into PHC and non-PHC investments. They estimated that over two-thirds of the estimated additional resources needed for SDGs are for PHC services, which is approximately an additional US\$38 per capita per year during 2026-2030, in these 67 LMICs.

In order to conduct these resource tracking (RT) related activities, many RT methods and tools have been developed over time. For example, tracking of national health care expenditure has helped evolve national health accounting methods into the current system of health accounts framework represented by SHA 2011. Many costing tools have been developed and used to track the current spending at the health care provider level and/or for priority intervention programs. A number of other 
RT methods and tools exist and are widely used that go beyond expenditure tracking. These include Fiscal Space Analysis (FSA), Public Expenditure Reviews (PERs), Public Expenditure Tracking Surveys for health (PETS), tracking Development Assistance for Health (DAH), and Benefit Incidence Analyses (BIAs). Some of these resource tracking methods and tools are focused specifically on types of programs such as NHA subaccounts for maternal and child health, Joint Reporting Form-immunization (JRF), and National AIDS Spending Assessment (NASA). However, most of these efforts do not focus on PHC, except for some of the BIA analyses. Many of these methods and tools were developed as measurement and monitoring tools rather than as analytical tools to understand policy issues for PHC systems improvement. A review of the details of these methods and tools is provided in Chapter 2.

For the most part, these RT methods and tools have been used to ensure that international donors are coordinating their efforts and honoring their aid commitments, and that developing countries are meeting spending targets. Moreover, they serve as essential ingredients for health sector reviews that assess the effectiveness of current investments and have become key inputs for health sector planning exercises. However, the value of many of these tracking efforts have not been fully optimized for improving the financing and performance of health systems due to various gaps and constraints. These gaps include, but are not limited to, the following:

- Fragmentation. Many RT methods and tools are developed to focus on only one or two aspects of health care financial management issues, such as budget and/or expenditure issues. Consequently, these analyses do not provide full information and do not capture the dynamics of decision processes of resource allocation, execution, and utilization issues within the health system. This may force policy directions to narrowly focus on one or two problematic areas, rather than developing policies in a more holistic approach that could be more effective in improving the health financing system.

- Focus on measurement rather than explanation. There is often a dearth of qualitative information to tell the story behind the numbers and statistics. Many RT methods and tools are often developed as 
comprehensive quantitative data collection and statistical exercises, without sufficient qualitative information to explain the context behind the quantitative information. As a result, we may know something is broken but not understand the factors behind the dysfunction or what to do to address it.

- Lack of linkage between RT and goals/impacts. Many RT activities only focus on financial information, without linking it to the output/ outcome that the investment is aimed to produce.

- Retrospective and often delayed measurement. Many RT methods and tools focus on the expenditure that already occurred in the health care system. This approach often means time lags of 1-2 years from analysis to decision-making and does not provide concurrent information on the issues that need to be addressed by the policymakers and health care managers in a timely fashion.

- Lack of clear policy recommendation/intervention to improve public financial management with robust evidence. Many public RT efforts stop after problems are identified. Very few of them provide realistic solutions for improvement or test and evaluate such solutions.

- Lack of cross-country/-system learning. There has been a persistent absence of common agreed definitions, framework, methods, and tools for the purpose of cross-country comparison analysis that allows countries to confidently learn from each other. Almost all public RT focuses on within-country before-after intervention comparison, without considering cross-country/-system learning.

\section{The Resource Tracking and Management (RTM) Framework and its Added Value}

Investment in PHC reflects the financial resources used to pay for the labor, capital, drugs, supplies, and other inputs required to deliver PHC services to the population. Understanding the investments in PHC, as well as their utilization, has been considered as essential information to inform policy development and planning to improve both the delivery of primary care activity and patient health outcomes. RT continues to be considered a critical effort to collect information related to the following: 
- How much do countries invest in health and health care?

- How much do different actors such as government, insurance companies, households, and donors contribute to the investment in health?

- What kinds of health care services and commodities are being financed?

- Which health care providers deliver these services and commodities?

- What are the financial management systems in place to manage the financial resources in the health care system?

- What are the purchasing mechanisms between different financial management and service delivery agencies?

- Who are the beneficiaries from various health care investments, especially from public investments?

The RTM framework, introduced in this book, incorporates a wide range of existing RT methods, tools, and activities into an end-to-end RT system to answer the critical policy questions outlined above, analyzing how resources are mobilized, allocated, and used from sources of financing to the beneficiaries who obtained health care services that are funded by these sources of financing. The overarching value addition is to change the focus of RT efforts from simply measuring resources to identifying policies and actions for health financing to be effective in improving outcomes. The RTM framework partitions RT efforts into five major steps: resource mobilization, resource allocation, resource utilization, resource productivity, and resource targeting. This is shown in Figure 1.

- Resource mobilization. The first level of the end-to-end RT framework is resource mobilization, which measures how much financing is available for health and the determinants of the total resource envelope for health/primary health care at the national and sub-national levels in each country. The main questions asked under this part of the framework consist of how the resource envelope for health is determined and achieved at national, regional, and local levels, under the specific fiscal constraints, and what measures can be used to increase the financing for health care. 


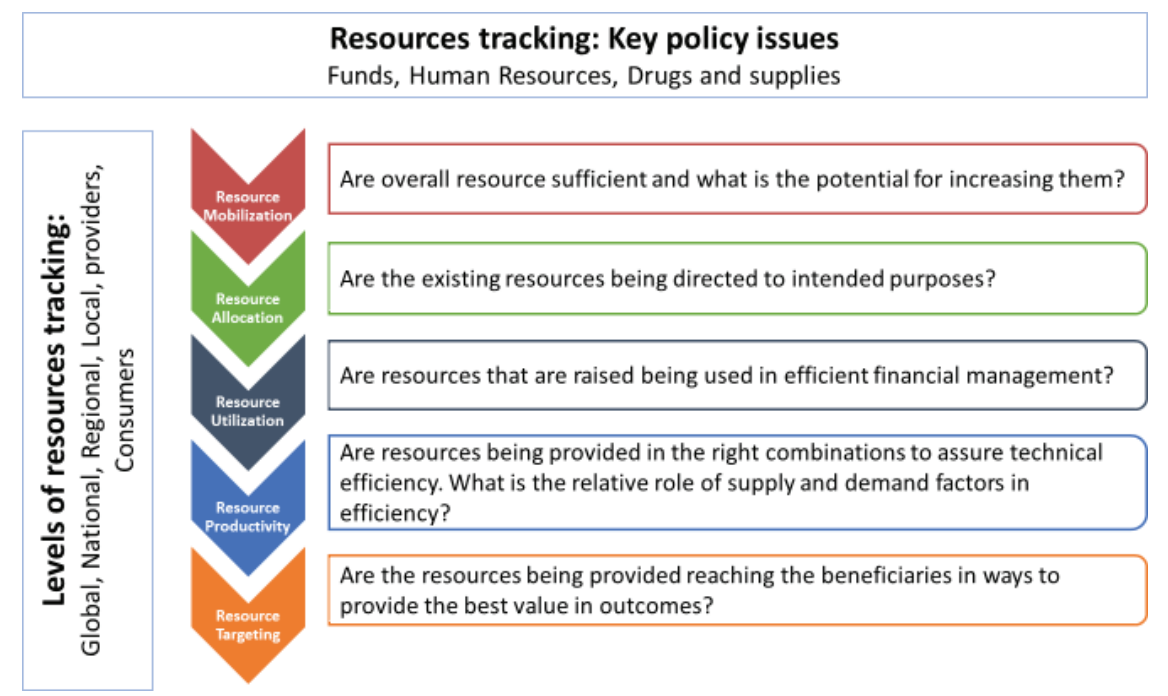

Figure 1: End-to-end Resource Tracking Framework

- Resource allocation. Resource allocation explores the ways that resources are allocated to different health functions. More specifically, this component focuses on the following: (1) the flow of resources through a country's system(s); (2) allocation of resources to PHC compared to other levels of care; and (3) determinants for allocation resources to health, and specifically primary care, including policies, budgeting and planning processes, and allocation norms.

- Resource utilization. Resource utilization addresses how much of the budgeted funds are utilized (released and actually expended). This includes not just the amounts of the budget utilization but also analysis of the causes of underutilization of budgeted amounts, such as the timing of the budget releases and differences across different components of budget (such as budget for salary vs capital investment vs drug and supply expenditure). It also includes the investigation of bottlenecks to fund use (such as procurement constraints) as well as the factors that drive successful execution of budgeted funds (such as effective financial management systems). The sources of effective budget utilization problems are also analyzed in terms of horizontal 
flows (such as from ministries of finance to ministries of health) and vertical flows (such as from federal to state or to further lower levels of government and from government agencies to service delivery facilities) to identify strategies for improving budget effectiveness.

- Resource productivity. Resource productivity is concerned with how effectively funding is being translated into services. The efficiency of turning inputs into outputs and the quality of outputs are both taken up at this level. Mobilizing additional resources for primary care alone cannot guarantee results. They need to be used to purchase the right inputs, assuming such inputs are available. Next, those inputs have to be used effectively to deliver services, a result that depends on a range of factors including proper planning, organization performance, and well-functioning internal and external accountability mechanisms. This analysis requires bringing together financial and service delivery information, such as output and outcome indicators to assess efficiency and effectiveness of health spending, as well as identifying potential interventions to improve the effectiveness of that spending.

- Resource targeting. Resource targeting examines the distributional effects of public spending and health program benefits, including whether such funding is reaching the intended beneficiaries. The findings are mixed on whether government health spending sufficiently reaches intended beneficiaries for primary care services. This is often measured using BIA, which assesses the degree to which public spending is pro-poor. This same approach could be used to assess the overall health system performance based on the distribution of service benefits to other prioritized groups in populations (McIntyre and Ataguba, 2011).

Table 2 links the different levels of the RTM framework and existing RT methods and tools. This indicates that there is no simple one-to-one relationship between tools and levels in the framework. Many RT methods and tools can contribute to the policy issues at multiple levels in the RTM framework. For example, fiscal space analysis and cost analysis can be used in resource mobilization and in resource productivity analysis as well when combined with additional information on service utilization. Public 
Table 2: RT Methods Tools Classified within RTM Framework

\begin{tabular}{|c|c|c|}
\hline $\begin{array}{l}\text { Levels of RTM } \\
\text { Framework }\end{array}$ & Key Policy Issues & Selected Methods and Tools \\
\hline $\begin{array}{l}\text { Resource } \\
\text { mobilization }\end{array}$ & $\begin{array}{l}\text { Allocative efficiency at } \\
\text { the macro-level }\end{array}$ & $\begin{array}{l}\text { Fiscal Space Analysis (FSA), Cost } \\
\text { analysis (Cost Plus, Onehealth } \\
\text { Tool) }\end{array}$ \\
\hline $\begin{array}{l}\text { Resource } \\
\text { allocation }\end{array}$ & $\begin{array}{l}\text { Allocative efficiency } \\
\text { within the health system }\end{array}$ & $\begin{array}{l}\text { Public Expenditure Review (PER), } \\
\text { Planning/budget analysis, Cost } \\
\text { analysis, National Health Account } \\
\text { (NHA)/System of Health Account } \\
\text { (SHA), Political analysis }\end{array}$ \\
\hline $\begin{array}{l}\text { Resource } \\
\text { utilization }\end{array}$ & $\begin{array}{l}\text { Administrative efficiency } \\
\text { within the government/ } \\
\text { health system }\end{array}$ & $\begin{array}{l}\text { Public Expenditure Tracking } \\
\text { Surveys (PETs) }\end{array}$ \\
\hline $\begin{array}{l}\text { Resource } \\
\text { productivity }\end{array}$ & $\begin{array}{l}\text { Technical efficiency at } \\
\text { every delivery level }\end{array}$ & $\begin{array}{l}\text { Quantitative Service Delivery } \\
\text { Survey (QSDS), or Facility } \\
\text { Survey }\end{array}$ \\
\hline $\begin{array}{l}\text { Resource } \\
\quad \text { targeting }\end{array}$ & $\begin{array}{l}\text { Allocative efficiency/ } \\
\text { effectiveness }\end{array}$ & $\begin{array}{l}\text { Benefit Incidence Analysis (BIA), } \\
\text { Political analysis }\end{array}$ \\
\hline
\end{tabular}

expenditure reviews have been used to address government budget/ resource allocation issues and can be used for the analyzing budget utilization as well and can be used for the efficiency and effectiveness analyses when linked with other information.

Applying the RTM framework allows for a more comprehensive country-level analysis to uncover bottlenecks and issues inhibiting better health system performance across the continuum of health resource flows. Policy questions can be identified, and remedial actions can be proposed by organizations using existing health investment tracking data, with additional data collection within the defined RTM framework approach. The goal is a more efficient and effective health financing system. The framework and "filter" questions used enable policymakers to identify the most critical issues along the health resource continuum and prioritize policy actions according to the following:

- political will;

- political opportunity and priority; 
- technical feasibility and capacity;

- whether major investments are already made by government or other stakeholders to address the identified critical challenges.

\section{The Limitations, Objectives, Structure, and Scope of the Book}

\subsection{Limitations}

Let us begin this section by discussing limitations. This book is not a methodology and "how to" book or a manual for RT. The primary purpose is to introduce the end-to-end RTM framework, to demonstrate its applications in the countries as the comprehensive analytical tool and to provide critical information to policymakers and practitioners to improve the financing of PHC system. Therefore, the health care financing policy and financial management issues within the flow of funds for PHC system development and service delivery are the focus of this volume, not the methodology and tools themselves.

We have focused here on country case studies to demonstrate the application of the RTM framework for PHC financing and system strengthening, giving PHC's importance in system development and its roles in achieving health-related SDGs. One of biggest challenges for RT for PHC is the definition of PHC. As we have described at the beginning of this chapter, PHC was coined as the most basic level of care in a structured health system almost a century ago. The definition of PHC is still evolving, and the PHC system varies greatly from country to country depending on its service coverage, providers who deliver these services, and administrative and financing structure of the health care system. Rather than attempting to discover, redefine, or open the discussion about these existing definitions, the case studies in this book simply follow the definition of PHC adopted in each country's system.

Tracking financial resources for health is about the money in health systems, and also reflects the effects of much broader health policy issues. Health "resources" are not only financial but also human resources, equipment, drugs, other commodities, and many other elements including those contributed by the communities affected by health and health care. 
The resources come from public, health insurance, and/or other pooled fund management agencies, donors and development partners, and out-ofpocket payment at the point of services by the patients and from communities. Resources can be used for overall health services, a subset of services such as PHC or non-PHC, or priority interventions, such as HIV, TB, and malaria. The RTM framework, as well as the methods and tools, can be applied to any set of aspects of health care system described above. Rather than attempting to address all of these issues in a comprehensive way, the focus of this book is on government financing for PHC only. In addition, we did not attempt to cover all RT methods and tools that can be applied to each stage of RTM.

\subsection{Objectives}

This book introduces and explicates the RTM end-to-end RT framework. This framework attempts to mitigate some of the shortfalls in the existing RT efforts from the following aspects:

- Continuous and dynamic end-to-end tracking: from sources to the beneficiaries.

- Focusing on policy issues: efficiency and effectiveness of resource allocation and utilization of PHC.

- From quantitative accounting approach to both quantitative and qualitative policy-oriented approach.

- Use both quantitative and qualitative information to identify potential factors that affect appropriate flow of funds within government agencies and from government to service delivery and to targeted populations.

- Linking resources with outputs/outcomes and with the beneficiaries.

In addition, this book compiles detailed results from the most recent RTM-based RT efforts for PHC in select countries. These results include chapters on specific analytical applications of the different levels of the RTM framework as well as overviews from selected countries on how relevant questions for analysis were developed and how the parts link together into a more coherent whole. This demonstrates how to use this 
RTM framework to bring a set of separate RT efforts at different stages of flow of funds into a comprehensive "storyline": if we want to build a functional PHC system to address access, quality, and equity issues, what are the key (public) financing issues that researchers/technical advisors/ policymakers need to address in addition to more resources.

The key audiences of this book go beyond the health economist. The key audiences include researchers, especially operational researchers, technical assistant consultants, policy advisors, policymakers and managers, and students who want to work in this area for their career development and to improve the performance of primary health care worldwide.

\subsection{Structure}

The structure of this book comprises sections representing the five levels of the RTM framework: resource mobilization, resource allocation, resource utilization, resource productivity, and resource targeting. In addition, chapters on specific countries explore how the analyses at these five levels came together in national policymaking.

The book starts with this Introduction in Part I. Two chapters have been included in this part: the introduction chapter and a literature review chapter. Chapter 1 reviews the objectives, the RTM framework and its added value, and the target audiences. The context and previous global experiences with health resource tracking and RTM-related efforts are reviewed in Chapter 2.

The main body of the book has been divided into five parts, Parts II-VI, each of them targets analyses and policy issues associated with one specific stage of the flow of funds within the RTM framework. A select set of country case studies or global/regional study summaries have been included in each of these five parts. A total of 11 chapters have been included in Parts II-VI. The purpose of this book is to provide some selected examples and details regarding the policy relevance, the feasibilities, and the potential challenges encountered in doing these types of work at both country and global/regional levels.

The book concludes in Part VII with the use of the RTM framework to bring all critical policy issues across all different stages of the flow of funds within the health care system into a holistic storyline with real 
country examples from Ethiopia, India, and Nigeria. These comprehensive country RTM case studies showcase how RT data, including both quantitative and qualitative information, was leveraged to comprehensively analyze the flow of resources through the health systems with a focus on primary care service delivery and how these findings were used to inform policymakers and resulted in necessary policy dialogue or actions to improve the efficiency, effectiveness, and/or equity of health financing at country level.

\section{References}

Bitton, A. Ratcliffe, H.L., Veillard, J.H., Kress, D.H., Barkley, S., Kimball, M., Secci, F., Wong, E., Basu, L., Taylor, C., Bayon, J., Wang, H., Lagomarsino, G. and Hirschhorn, L.R. (2017). Primary health care as a foundation for strengthening health systems in low- and middle-income countries. J. Gen. Intern. Med. 32(5), 566-571.

Frenk, J. (2009). Reinventing primary health care: The need for systems integration. Lancet 374(9684), 170-173.

IMF. (2001). IMF's Fiscal Affairs Department and the World Bank's Poverty Reduction and Economic Management Network. Tracking of PovertyReducing Public Spending in Heavily Indebted Poor Countries (HIPCs). Washington, DC: IMF and The World Bank. Available at https://www.imf. org/external/np/hipc/2001/track/.

Johnson, A. Vision into action. Address to the eleventh annual conference and exhibition of the National Health Service Alliance. International Conference Centre. Bournemouth, U.K., October 16, 2008.

Maele, N.V., Xu, K. Soucat, A., Kutzin, J., Aranguren, M. and Wang, H. (2018). Measuring primary health care expenditure in low and lower-middle income countries. Conference Paper, Astana, Kazakhstan, October 25-26, 2018.

McIntyre D. and Ataguba J.E. (2011). How to do (or not to do) ... a benefit incidence analysis. Health Policy Plan. 26(2), 174-182.

Millis, J.S. (1966). Citizens Commission on Graduate Medical Education. Chicago, IL: American Medical Association.

Naledi, T., Barron, P. and Schneider, H., (2011). Primary health care in SA since 1994 and implications of the new vision for PHC re-engineering. S. Afr. Health Rev. 1, 17-28.

National Health Accounts Cell, Ministry of Health and Family Welfare (In collaboration with WHO India Country Office). (2009). National Health 
Accounts 2004-2005 India. New Delhi: Ministry of Health and Family Welfare, Government of India.

Office of the Health Insurance Commissioner. (2014). Primary Care Spending in Rhode Island: Commercial Health Insurer Compliance.

Ramana, G., Chepkoech, R. and Walelign, N. (2013). UNICO Studies Series 5, Improving Universal Primary Health Care by Kenya: A Case Study of the Health Sector Services Fund. Washington, DC: The World Bank.

Selvaraju, V. and Annigeri, V. (2001). Trends in public spending on health in India. A background paper for Commission on Macroeconomics and Health (India Study). New Delhi: National Institute of Public Finance and Policy.

Stenberg K., Hanssen O., Tan-Torres Edejer T., Bertram M., Brindley C., et al. (2017). Financing transformative health systems towards achievement of the health Sustainable Development Goals: A model for projected resource needs in 67 low-income and middle-income countries. Lancet Glob. Health. 5, e875-e887.

Stenberg K., Hanssen O., Bertram M., Brindley C., Meshreky A., Barkley S., Tan-Torres Edejer T. (2019). Guide posts for investment in primary health care and projected resource needs in 67 low-income and middle-income countries: A modelling study. Lancet Glob. Health. 7, e1500-e1510.

Veillard, J., Cowling, K., Bitton, A., Ratcliffe, H., Kimball, M., Barkley, S., Mercereau, L., Wong, E., Taylor, C., Hirschhorn, L. and Wang, H. (2017). Better Measurement for Performance Improvement in Low-and-MiddleIncome Countries: The Primary Health Care Performance Initiative (PHCPI) Experience of Conceptual Framework Development and Indicator Selection. Milbank Quart. 95(4), 836-883. 